Jörn Walter und Nina Gasparoni

\title{
3. Themenbereich Epigenetik: von Zellidentitäten bis hin zu Krankheiten und Therapien
}

\subsection{Allgemeine Bedeutung und Prinzipien der Epigenetik}

Die Epigenetik hat sich in den vergangenen zwei Jahrzehnten zu einem Kernfach der Lebenswissenschaften entwickelt, mit einer breiten Strahlkraft in nahezu alle Bereiche der Biologie und Biomedizin. Epigenetische Prozesse betreffen die nachgesteuerte Regulation des Genoms, d. h. Prozesse, die „oberhalb“ bzw. „zusätzlich“ zum Genom stattfinden. Epigenetische Prozesse und Mechanismen sind universell in allen Lebewesen zu finden. Die Epigenetik erweitert unser Verständnis der Gensteuerung während der individuellen Entwicklung (Ontogenese), der Gen-Umwelt-Interaktion, der Vererbung und der molekularen Grundlagen von Erkrankungen.

Epigenetische Prozesse sind von allgemeiner Bedeutung für die eukaryotische Zelle: ${ }^{1}$ Sie steuern die zellspezifische Regulation von Genen - sowohl kurzzeitig als auch über lebenslange Zeiträume hinweg. Darüber hinaus steuern epigenetische Mechanismen generelle Prozesse der Organisation von Chromosomen im Zellkern sowie der chromosomenstabilität und -vermehrung.

Molekular betrachtet erfolgen epigenetische Prozesse als biochemische Markierungen (Modifikationen), die als zusätzliche (strukturelle) Signaturen entweder direkt an den DNA-Basen oder an den die DNA verpackenden Proteinen, den Histonen, angebracht werden. Diese Modifikationen werden „in situ“, d. h. ortsspezifisch, auf den Chromo-

1 Eukaryotische Zellen (von Pflanzen, Pilzen und Tieren) enthalten im Gegensatz zu den Zellen von Prokaryoten (Bakterien, Archaeen) einen mit einer Doppelmembran umhüllten Zellkern und verschiedene weitere abgegrenzte Kompartimente. 
somen im Chromatin ${ }^{2}$ etabliert. Umgekehrt können epigenetische Signaturen orts- und modifikationsspezifisch auch wieder entfernt werden. Epigenetische Veränderungen sind daher - im Gegensatz zu genetischen Veränderungen (Mutationen) - umkehrbar (umprogrammierbar).

Bestimmte epigenetische Modifikationen bewirken eine Öffnung und Zugänglichkeit, andere ein Verschließen und damit die Unzugänglichkeit des Chromatins in Chromosomen. Über diese differenzielle Zugänglichkeit, die über z. T. sehr komplexe Abläufe reguliert wird (siehe 3.2.1), werden dann ortsspezifisch weitere biochemische Prozesse wie z. B. das Ablesen (die Transkription) von Genen gesteuert.

Jeder Zelltyp besitzt ein zelltypisches epigenetisches „Eigenmuster“ seiner Chromosomen, d. h. eine genau geregelte und geordnete Abfolge geschlossener und geöffneter Chromosomenabschnitte. Dieses epigenetische Eigenmuster einer Zelle, auch Epigenom genannt, wird im Verlauf der Entwicklung einer Zelltypausbildung entsprechend genetisch festgelegter Entwicklungsprogramme etabliert. Einmal etabliert, kann das Epigenomprogramm dann über Zellteilungen hinweg stabil auf folgende Zellgenerationen vererbt (d. h. bei der Zellteilung kopiert) werden.

$\mathrm{Zu}$ Beginn jedes „neuen“ Lebens eines Säugers werden die epigenetischen Muster in den Keimzellen (Ei- und Samenzellen) bzw. im frühen Embryo weitgehend zurückgesetzt. Dieses Zurücksetzen, das auch als epigenetische Reprogrammierung bezeichnet wird, führt dazu, dass in den frühen Zellen des Embryos ein sehr hohes Niveau an offenem Chromatin an Genen erreicht wird. Dabei kommt es gleichzeitig zu einem Löschen der aus den Keimzellen kommenden epigenetischen Prägungen (vornehmlich DNA-Methylierung). In den nun Folgenden genetisch gesteuerten Differenzierungsprogrammen werden im Verlauf der Entwicklung präzise die neuen epigenomischen Muster einer

2 Als Chromatin wird die Gesamtheit des färbbaren DNA- und Proteinmaterials im Zellkern bezeichnet, aus dem die Chromosomen bestehen. Kernbestandteile des Chromatins sind kleine Untereinheiten, die sog. „Nukleosomen“. Diese setzen sich aus 8 Histonproteinen und der um diesen Proteinkomplex gewundenen DNA (ca. 150 Basen) zusammen. Histone gehören zu den am häufigsten in einer Zelle vorkommenden Proteinen. Sie sind evolutionär hoch konserviert, kommen also bei sehr vielen und auch sehr unterschiedlichen Organismen vor. Fast die gesamte DNA der Chromosomen ist in Nukleosomen organisiert (,verpackt“). Zwischen Nukleosomen liegen kurze Abschnitte freier DNA. Nukleosomen sind in aktiven und inaktiven Genbereichen unterschiedlich dicht auf den Chromosomen angeordnet. In genreichen Regionen erfolgt die Regulation einzelner Gene über die lokale Veränderung der Dichte von Nukleosomen. Generell bezeichnet man das Chromatin in genaktiven Bereichen als Euchromatin, d. h. „offenes oder zugängliches Chromatin“ (engl. „open or accessible chromatin"). Chromatinstrukturen in genarmen Regionen liegen in höheren Ordnungsstrukturen dagegen dichter „gepackt“ vor. Das Chromatin in diesen Regionen wird als Heterochromatin bezeichnet und ist in der Regel schwer oder unzugänglich für die Genregulation. 
Zelle etabliert und beibehalten. Diese epigenomischen Muster ändern sich zudem nach der Geburt und im Verlauf der weiteren Entwicklung bis hin zum Erwachsenenalter.

Mit zunehmendem Alter beobachtet man, dass die Epigenome in vielen Zellen altersabhängige Veränderungen aufweisen. Diese Veränderungen an bestimmten Stellen des Epigenoms können bspw. genutzt werden, um aus dem DNA-Methylom ${ }^{3}$ von Blutzellen präzise Rückschlüsse auf das relative biologische Alter der Person zu ziehen (Horvath, 2013). Die altersabhängigen Programmveränderungen führen u. a. dazu, dass bestimmte Immunzellen ihre Zellfunktionen nicht mehr wie junge Zellen ausführen können. Die Möglichkeit, gezielt eine epigenetische Verjüngung von Zellen zu erreichen, ist Gegenstand aktueller Forschung. Mit zunehmendem Alter kommt es neben regelmäßigen altersgerechten Veränderungen häufig auch zu spontan auftretenden Fehlern in epigenetischen Programmen. Solche auch von der Umwelt verstärkten epigenetischen Abweichungen (siehe 3.4.1) können nachhaltige Fehlentwicklungen der Genprogramme in Zellen auslösen. Besonders umfangreiche epigenetische Veränderungen beobachtet man in Krebszellen. Bei vielen Krebsarten kommt es zu massiven epigenetischen Veränderungen, in deren Folge viele Gene fehlgesteuert sind. Ein Grund dafür ist, dass epigenetisch wirkende Enzyme in Krebszellen häufig mutieren (d. h. genetisch verändert sind). In der Folge kommt es zu einer genomweiten Fehlfunktion dieser Enzyme und zu einer umfangreichen fehlerhaften epigenetischen Prägung der Epigenome von Krebszellen.

\subsection{Molekulare Grundlagen der Epigenetik}

\subsubsection{Histon-Modifikationen}

Wie oben angesprochen, ist die Ausbildung eines dichteren (heterochromatischen) oder eines lockereren (euchromatischen) Verpackungsgrades des Chromatins eine Folge epigenetischer Modifikationen. Für die Ausbildung dieser Verpackungszustände (aber auch Übergangsstrukturen) sind Kombinationen spezifischer euchromatischer bzw. heterochromatischer Histon-Modifikationen entscheidend. Histon-Modifikationen kommen in einer Vielzahl unterschiedlicher Formen und Positionen vor. Gegenwärtig sind > 100 verschiedene Modifikationen bekannt, die über alle vier Histontypen verteilt sind. Eines der Histone, das Histon H3, spielt im Hinblick auf die Modifikationen eine besonders prominente Rolle. Die meisten der gegenwärtig funktionell verstandenen His-

3 Der Begriff „Methylom“ bezieht sich auf genomweite Muster der „DNA-Methylierung“ (siehe 3.2.2). 
ton-Modifikationen beobachtet man an bestimmten Aminosäuren dieses Histons H3. ${ }^{4}$ Einige der Modifikationen findet man in offenem euchromatischen Chromatin, andere findet man spezifisch in geschlossenem heterochromatischen Chromatin.

Histon-Modifikationen werden stets ortsspezifisch, d. h. im Chromatin (,vor Ort in Nukleosomen“) durch modifizierende Enzyme, sog. „Writer“, gesetzt. Sie können umgekehrt von anderen demodifizierenden Enzymen (sog. „Erasern“) wieder ortsspezifisch entfernt werden. Entscheidend für die Ausbildung der veränderten Chromatinstruktur sind die spezifischen Kombinationen von Modifikationen an den Histonen (in Nukleosomen) und ihre Verteilung über benachbarte Nukleosomen. Die modifizierten Histone werden dann von sog. „Readern“, d. h. bestimmten Leseproteinen, erkannt und funktionell interpretiert. Die Art und Verteilung der Modifikationen und die Bindung von „Readern“" wird schließlich in engere oder lockerere Verpackungen der Nukleosomen „übersetzt“. Für das Lockern oder Schließen des Chromatins sind weitere Enzyme verantwortlich, die sog. „Remodeller“. Remodeller sind in der Lage, Nukleosomen im Chromatin aktiv zu verschieben, um so DNA „frei“zusetzen oder die Nukleosomen dichter anzuordnen. In genregulierenden Abschnitten des Genoms wird so eine Zugänglichkeit der DNA für weitere genregulatorische Faktoren (Transkriptionsfaktoren) geschaffen, während in permanent abgeschalteten Bereichen die DNA sehr eng und dicht in Nukleosomen verpackt bleibt.

Die dichte Verpackung in heterochromatisches Chromatin ist nicht nur wichtig für die negative Genregulation (nachhaltiges Abschalten). In manchen Regionen der Chromosomen, wie z. B. an den Enden der Chromosomen (Telomere) oder an den Centromeren ${ }^{5}$ ist die Ausbildung umfangreicher heterochromatischer Strukturen essenziell für die Chromosomenfunktion und -stabilität. In Krebszellen beobachtet man häufig die partielle Auflösung solcher heterochromatischen Regionen, was zu chromosomalen Instabilitäten (Chromosomenmutationen) in diesen Zellen beiträgt.

4 Aminosäuren sind die Bausteine der Proteine, also auch der Histone. Sie können biochemisch modifiziert werden. Dabei werden nicht alle Aminosäuren gleichermaßen verändert, sondern einige sind dafür anfälliger als andere. Auch die genaue Position im Protein spielt hierfür eine wichtige Rolle. Besonders die positiv geladene Aminosäure Lysin ist Ziel epigenetischer Modifikationen der Histone. Im offenen Euchromatin findet man Modifikationen am Histon H3 an den Positionen Lysin 4 (H3K4me3) und Lysin 27 (H3K4ac), während man im geschlossenen Heterochromatin Modifikationen an den Lysinen 9 (H3K9me3) und Lysin 27 (H3K27me3) beobachtet. (Die hier in Klammern angegebenen Buchstaben-Zahlen-Kombinationen geben die genaue Art und Position der Veränderung im Protein an.)

5 Telomere sind spezielle Strukturen an den Enden der Chromosomen, die diese vor dem Abbau schützen. Centromere sind Regionen in Chromosomen, die für die Aufteilung von Tochterchromosomen bei der Zellteilung essenziell sind. Beide Regionen, Centromere und Telomere, sind relativ genarm und zeichnen sich durch weite heterochromatische Chromatinverpackungen aus. 
Kartierung von Histon-Modifikationen

Die Kenntnis der Verteilung und Funktion von Histon-Modifikationen im Genom ergibt sich aus einer Vielzahl von verschiedensten Experimenten. Einen wichtigen Beitrag leistet hierbei die Epigenomik (siehe 3.3.1), in der die Verteilung der epigenetischen Modifikationen genomweit kartiert (auf Chromosomen verortet) wird. Für die Kartierung von Histon-Modifikationen nutzt man die Technik der Chromatin-Immunpräzipitation mit anschließender Next-Generation-Sequenzierung (NGS) (ChIP-Seq). ${ }^{6}$ Die so erstellten Histon-Modifikationskarten zeigen, dass eine Kartierung von sieben bis neun Histon-Modifikationen ausreicht, um das Genom grob in funktionell unterschiedliche Bereiche einzuteilen (Roadmap Epigenomics Consortium et al., 2015). Vergleiche von ChIP-SeqDaten verschiedener Zellen verschaffen einen Überblick über die Zellspezifität der Histon-Modifikationen. Aus dem Vergleich der Histonkarten gesunder und kranker Zelltypen kann man auf das Ausmaß der funktionellen epigenetischen Umprogrammierung erkrankter Zellen schließen (Karnik/Meissner, 2013).

Die Technologien zur Analyse von Histon-Modifikationen sind bislang nur bedingt für direkte diagnostische Untersuchungen einsetzbar, da große Mengen $\left(10^{5}\right.$ bis $\left.10^{6}\right)$ frischer Zellen benötigt werden, die häufig schwer zu isolieren sind, und die komplexen Experimente und Auswertungen unter sehr standardisierten Bedingungen durchgeführt werden müssen. Daten zum mRNA-Transkriptom ${ }^{7}$ und der DNA-Methylierung sind wesentlich einfacher zu gewinnen und spielen daher in der modernen Forschungsdiagnostik eine wesentlich prominentere Rolle (siehe 3.2.2).

\subsubsection{DNA-Methylierung}

DNA-Methylierung ist eine klassische, in nahezu allen Organismen vorkommende epigenetische Modifikation. Dabei wird eine Methylgruppe $\left(\mathrm{CH}_{3}\right)$ fest (kovalent) an

6 Bei der ChIP-Seq-Methode nutzt man hochspezifische Antikörper, die bestimmte Modifikationen in Histonen erkennen und fest an diese binden. Man isoliert intaktes Chromatin einer Zelle, zerteilt dieses in Nukleosomen und reichert dann mithilfe der Antikörper die Nukleosomen an, in denen diese modifizierten Histone vorkommen. Dann isoliert man die DNA aus der angereicherten Nukleosomenfraktion und bestimmt diese durch Hochdurchsatzsequenzierung. Nach einer bioinformatischen Auswertung dieser Daten erhält man eine Anreicherungskarte entlang des Genoms/Chromosoms, wo exakt bestimmte Histon-Modifikationen spezifisch zu finden sind. Mithilfe unterschiedlich spezifischer Antikörper können so nacheinander verschiedene Histon-Modifikationen entlang der DNA „kartiert" werden.

7 Im Zuge eines Prozesses, der „Transkription“ genannt wird, dient die DNA als Vorlage für den Aufbau der RNA. Das Transkriptom bezeichnet die Gesamtheit aller von der DNA in RNA transkribierten Gene, d. h. alle RNA-Moleküle, die zu einem bestimmten Zeitpunkt in der Zelle vorliegen. 
bestimmte Bausteine der DNA (Cytosinbasen, abgekürzt mit dem Buchstaben C) gebunden. Genau genommen wird die Methylgruppe durch bestimmte Enzyme (DNAMethyltransferasen, DNMTs) auf die Cytosinbasen in der DNA übertragen. Man unterscheidet dabei zwischen DNMTs, die DNA-Methylierung neu setzen, und solchen, die diese bei der Zellteilung kopieren können. DNA-Methylierung ist eine sehr stabile Modifikation und kann auch in isolierter DNA älterer DNA-Proben noch detektiert werden.

\section{Mechanismen der DNA-Methylierung}

In Säugern und im Menschen tritt die DNA-Methylierung fast ausschließlich an Cytosinbasen in der Basenabfolge Cytosin-Guanin ( $\mathrm{CpG}$ ) auf. ${ }^{8}$ DNA-Methylierung lässt sich entsprechend als digitales oder binäres Signal entlang der DNA lesen: 0 = Methylierung am CpG ist nicht vorhanden und 1 = Methylierung am CpG ist vorhanden. Im Vergleich $\mathrm{zu}$ den vielgestaltigen Histon-Modifikationen sind die DNA-Methylierungsmuster mit ihren binären Abfolgen daher relativ einfach zu erfassen. Man beobachtet klare zellspezifische Abfolgen der Dichte und Ausprägungen dieser binären DNA-Methylierungsmuster. Entsprechend kann man die zell-spezifische Verteilung von DNA-Methylierungsmustern nutzen, um (bioinformatisch) zellspezifische, digitale epigenetische Signaturen zu ermitteln und diese genau zu quantifizieren (zählen). Die Verteilung der zellspezifischen DNA-Methylierungsmuster zeigt dabei eine weitreichende Korrelation mit der An- und Abwesenheit von bestimmten Histon-Modifikationen.

Analog zu den Histon-Modifikationen wird die DNA-Methylierung ortsabhängig als epigenetisches Signal von speziellen DNA-bindenden Proteinen („Readern“) erkannt. Diese „Reader“ übersetzen das binäre epigenetische Signal in „Funktion“. Die Erkennung erfolgt häufig im Wechselspiel mit räumlich benachbarten Histon-Modifikationen, d. h. die „Reader“ bilden eine funktionelle Brücke zwischen den epigenetischen Ebenen. Je nach ortsspezifischer Lage, dem Methylierungszustand sowie dem Histon-Modifikationskontext der Nukleosomenumgebung wird die DNA-Methylierung von den „Readern“ entweder als repressives (häufig) oder aktivierendes (seltener) epigenetisches Signal interpretiert. DNA-Methylierung dient dabei in weiten Teilen des Genoms als wichtiges Basissignal zur Stilllegung repetitiver DNA-Strukturen (im Heterochromatin) und springender Gene (Retrotransposons). Darüber hinaus wird eine Anzahl von Genen (z. B. auf dem X-Chromosom) über DNA-Methylierung nachhaltig abgeschaltet, um so die Gendosis (in weiblichen Zellen) zu kontrollieren.

8 Die Basenfolge CG ist spiegelbildlich symmetrisch auf beiden komplementären DNA-Strängen. Diese Sequenzsymmetrie ermöglicht es, dass DNA-Methylierung nach der halb konservativen DNAReplikation auf den nicht methylierten Tochterstrang (Zellen) kopiert und basengenau vererbt werden kann. 
Genetische Unterschiede und individuelle Variation

Genomweite DNA-Methylierungsmuster werden in nicht unerheblichem Ausmaß durch genetische Veränderungen (individueller Personen) mitbeeinflusst. Mit anderen Worten, genetische Unterschiede können DNA-Methylierungsmuster lokal und zelltypspezifisch beeinflussen (Scherer et al., 2021). DNA-Methylierungsmuster von genetisch identischen eineiigen Zwillingen sind entsprechend ähnlicher - trotzdem unterscheiden sich Zwillinge individuell an einigen Positionen. Methylierungsmuster können daher anders als genetische Muster zur Unterscheidung genetisch identischer Personen herangezogen werden (Souren et al., 2019).

Die Epigenome eines Menschen weisen in vielen oder in allen Zellen individuelle Variationen in geringem, aber messbarem Ausmaß auf. Man geht davon aus, dass solche individuellen Veränderungen während der frühesten Phase der Embryonalentwicklung entstehen. In dieser Phase werden die DNA-Methylierung und die Histon-Modifikationen genomweit sehr stark verändert. Der biologische Grund für diese epigenetische Reprogrammierung ist unklar. Es wird vermutet, dass die (Epi-)Genome hierdurch in eine Art epigenetischen Urzustand versetzt werden, um nachfolgend im Verlauf der Entwicklung eindeutige, zellspezifische epigenetische Muster kontrolliert neu setzen zu können. Im Reprogrammierungsprozess kann es dann zu spontanen, individuellen Fehlern kommen. In der Tat beobachtet man individuelle Veränderungen bei eineiigen Zwillingen.

DNA-Methylierung in Insekten und Pflanzen

DNA-Methylierung existiert in nahezu allen multizellulären Organismen mit Ausnahme der klassischen entwicklungsbiologischen Modellorganismen Drosophila melanogaster (Fruchtfliege) und Caenorhabditis elegans (Fadenwurm). DNA-Methylierung hat in allen Organismen, in denen sie vorkommt, eine genregulatorische Funktion. In Insekten (Bienen, Termiten, Ameisen) findet man evolutionär konservierte, hochentwickelte Systeme für DNA-Methylierung. Diese dienen der Steuerung von Genen, die für die morphologischen Veränderungen während der Reproduktion wichtig sind, aber vermutlich auch erlerntes und angepasstes Verhalten steuern (Wang et al., 2006; Maleszka, 2008). Bei Bienen wurde bspw. beobachtet, dass die Differenzierung von Königinnen durch Ernährungsstoffe beeinflusst wird und dass sich Königinnen und verschiedene Arbeiterinnen epigenetisch unterscheiden (Lyko et al., 2010).

Auch in Pflanzen spielt die DNA-Methylierung eine wichtige, wenn nicht gar entscheidende epigenetische Rolle (Henderson/Jacobsen, 2007). Bei Pflanzen wird eine Reihe vererbbarer, adaptiver epigenetischer Effekte beobachtet, die auf DNA-Methylierung beruhen (Hirsch et al., 2012). Pflanzen verfügen über ein sehr hoch entwickel- 
tes System zur Kontrolle der DNA-Methylierung. Die Verteilung der DNA-Methylierung ist zudem viel komplexer und neben der Methylierung an CpGs können auch andere Sequenzen methyliert werden. Zudem beobachtet man genspezifische, sehr spezialisierte Formen epigenetischer Regulierung, die direkt lokal über nicht-kodierende RNAs vermittelt werden (siehe 3.2.3). In Pflanzen wurde auch erstmalig nachgewiesen, dass DNA-Methylierung aktiv durch DNA-Reparaturprozesse entfernt werden kann (Zheng et al., 2008). Analoge Mechanismen wurden später auch in einigen Wirbeltieren (Zebrafisch und Xenopus) sowie in Säugern (Maus und Mensch) nachgewiesen (Gehring et al., 2009) und sind gegenwärtig die einzige nachgewiesene Möglichkeit, DNA-Methylierung direkt ortsspezifisch zu entfernen.

\section{Oxidative Modifikationsformen und DNA-Demethylierung}

Im Säuger und dem Menschen gibt es eine zusätzliche Spezialisierung. DNA-Methylierung kommt hier in weiteren Modifikationsformen vor - vornehmlich in Stammzellen und in Zellen des Gehirns. 5-Methylcytosin (5mC) wird dabei enzymatisch durch TETEnzyme ${ }^{9}$ stufenweise in drei Oxidationsstufen modifiziert. ${ }^{10}$ Es gibt klare Hinweise darauf, dass oxidative Modifikationen für den DNA-Methylierungsverlust in der frühen Keimzell- und Embryonenentwicklung wichtig sind (Wossidlo et al., 2011; Seisenberger et al., 2013, Arand et al., 2015). Die Bedeutung der oxidativen Formen der DNA-Methylierung für genregulatorische Prozesse ist allerdings noch nicht wirklich verstanden und Gegenstand weitreichender Forschung.

In Stammzellen werden umfassende epigenetische Veränderungen beobachtet, die mit oxidativen Modifikationen einhergehen. Auslöser dieser Veränderungen sind entweder bestimmte Kultivierungsbedingungen oder die Differenzierung von Stammzellen in Vorläuferzellen, z. B. von Neuronen. In beiden Fällen kommt es zu einer vorübergehenden Zunahme oder Abnahme der oxidativen DNA-Modifikationen. Dies legt den

9 TET-Enzyme sind eine Familie von sog. ,ten-eleven translocation“-Methylcytosin-Dioxygenasen, also Enzymen, die maßgeblich an der Demethylierung der DNA beteiligt sind.

$10 \mathrm{Zu}$ den oxidativen Modifikationen und dem genauen biochemischen Ablauf der Demethylierung: Als erste Oxidationsstufe entsteht aus 5-Methylcytosin (5mC) 5-Hydroxymethylcytosin (5hmC), danach 5-Formylcytosin (5fC) und schließlich 5-Carboxycytosin (5caC). 5-Hydroxmethylcytosin $(5 \mathrm{hmC})$ ist wesentlich langlebiger und kommt angereichert in Neuronen vor. Es wird von speziellen Proteinen („Readern“) erkannt und anders als $5 \mathrm{mC}$ gelesen und interpretiert. Bei der Replikation kommt es z. B. zu einem Nicht-Kopieren von 5hmC-haltiger DNA. Die höheren Oxidationsstufen 5-Formylcytosin und 5-Carboxycytosin dienen als Erkennungssignale für eine aktive Demethylierung durch DNA-Glycosylasen, d. h. Enzyme, die eine basengenaue DNA-Reparatur, den Ersatz des $5 \mathrm{fC}$ oder $5 \mathrm{caC}$ durch $\mathrm{C}$, erwirken. 
Schluss nahe, dass schnelle, dynamische Veränderungen der DNA-Methylierung mit einer vermehrten Präsenz oxidativer Formen einhergehen.

Das gehäufte Vorkommen von 5-Hydroxymethylcytosin $\left(5 \mathrm{hmC}^{7}\right)$, einer ersten Oxidationsform von $5 \mathrm{mC}$, im Gehirn wiederum deutet an, dass Formen der oxidativen DNAMethylierung für kurzfristige epigenetische Umschaltungen von Genprogrammen in Zellen des Gehirns, vornehmlich Neuronen, genutzt werden könnten. Oxidative Modifikationen scheinen jedoch eine wichtige Schutzfunktion gegen einen Zelltod von Gehirnzellen aufzuweisen, wie Versuche zu Schlaganfall oder Ischemien gezeigt haben (Miao et al., 2015). In adulten Neuronen und auch anderen Zellen des Gehirns beobachtet man mit zunehmendem Alter eine Erosion der DNA-Methylierung. Da diese Zellen sich nicht mehr teilen (replizieren), liegt die Vermutung nahe, dass diese Veränderungen auf oxidativ verursachte Demethylierungsprozesse zurückzuführen sind (Gasparoni et al., 2018).

\section{Bestimmung und Kartierung der DNA-Methylierung}

DNA-Methylierung kann mithilfe verschiedener Verfahren auf die Base genau bestimmt und gemessen werden. Das am meisten genutzte Verfahren ist die gesamtgenomische Kartierung durch DNA-Sequenzierung nach Bisulfit-Behandlung (,whole genome bisulfite sequencing“, WGBS). Durch die Chemikalie Bisulfit wird die DNA so verändert, dass nach einer Vervielfältigung der DNA alle Cytosine (also die Base C) im Genom, die ursprünglich nicht methyliert waren, in Thymine (also die Base T) „umgewandelt" werden. Entsprechend kann man in der DNA-Sequenz die methylierten Positionen direkt identifizieren. Bisulfit-gestützte Verfahren zur DNA-Methylierungsdetektion werden auf vielfältige Art und Weise in der molekularen Labordiagnostik eingesetzt. Das zurzeit gängigste System nutzt dazu sog. „Bead-arrays“, ${ }^{11}$ mit denen bis zu 850.000 Methylierungspositionen (d. h. ca. 3,5 \% aller CpGs im Genom) systematisch bestimmt werden können. Dieses Verfahren wird zunehmend für die unterstützende Krebsdiagnostik eingesetzt, aber auch für Studien, in denen man die Veränderung epigenetischer Muster in komplexen physischen und psychischen Erkrankungen bestimmen möchte (Birney et al, 2016).

11 Bead-Arrays sind kleine „Biochips“, mit denen die DNA-Methylierungslevel an individuellen CpGs untersucht werden können. Das Prinzip basiert auf sog. „Beads“ mit ortsspezifischen Sonden, welche bestimmte Bisulfit-konvertierte DNA-Abschnitte binden und an einer CpG-Position enden. Je nach Spezifität der Sonde für methylierte oder unmethylierte Abschnitte bzw. des Methylierungszustands des zu untersuchenden CpGs werden die Sonden um einen fluoreszenzmarkierten DNA-Baustein (Nukleotid) verlängert. Der Methylierungsgrad kann dann durch Messung des Fluoreszenzsignals berechnet werden. 


\subsubsection{Nicht-kodierende RNAs}

Zusätzlich zu den bekannten chemischen Modifikationsebenen an Histonen und der DNA spielen nicht-kodierende RNAs (ncRNAs) ${ }^{12}$ eine bedeutende Rolle für die Epigenetik (Holoch/Moazed, 2016). RNA-vermittelte epigenetische Regulationsprozesse wurden ursprünglich in Pflanzen und später in nahezu allen höheren Organismen entdeckt. NcRNAs beeinflussen ein breites Spektrum genregulatorischer und epigenetischer Abläufe. NcRNA-vermittelte Prozesse spielen sich grob auf zwei Ebenen ab: Zum einen können ncRNAs direkt die Stabilität der mRNA beeinflussen. Dies wird über Prozesse der RNA-Interferenz ${ }^{12}$ vermittelt. Zum anderen können ncRNAs auch direkt ortsspezifisch im Chromatin wirken und hier das Setzen, Interpretieren oder Entfernen anderer epigenetischer Modifikationen beeinflussen.

Solche über ncRNAs initiierten epigenetischen Modifikationen können dann unabhängig von der Präsenz der ncRNA stabil weiter vererbt werden. Das enge Wechselspiel zwischen orts- und genspezifisch wirkenden ncRNAs und Histon- bzw. DNA-Modifikationen beobachtet man in vielen Modellorganismen wie Hefe, Fruchtfliege, Fadenwurm, Maus und der Ackerschmalwand (Arabidopsis thaliana).

Der Mechanismus der RNA-Interferenz (RNAi) wird zu den epigenetischen Mechanismen gezählt, da er „zusätzlich“ zum Genom stattfindet und zur Genregulation beiträgt. RNAi wird in Pflanzen als RNA-vermittelter Abwehrmechanismus gegen Viren/ Pilze genutzt. In Pflanzen kann sich die miRNA vom Ort der ersten RNAi-Reaktion (virusinfizierte Zelle) aus systematisch über die Pflanze verbreiten und so eine breite abwehrende Wirkung auslösen.

Im Menschen sind die RNAi-Mechanismen zu genregulatorischen Prozessen evolviert. Im Genom des Menschen gibt es Hunderte miRNA-Einheiten, die über das Genom verteilt sind. MiRNAs werden in sehr zellspezifischen Mengen gebildet und üben wichtige Regulationseffekte auf mRNAs ${ }^{13}$ und damit die Genprogramme der Zellen aus.

12 Als nicht-kodierende RNAs bezeichnet man kurze oder auch längere RNA-Moleküle, die als RNAs vom Genom abgelesen (transkribiert) werden, aber keine proteinkodierende Funktion haben. NcRNAs wirken direkt als RNAs im Zellkern (im Chromatin) oder im Zellplasma (mittels RNA-Interferenz, RNAi). RNA-Interferenz erfolgt, indem kurze, 22-25 Basenpaar lange miRNAs (mikroRNAs) eine sequenzspezifische Bindung von Enzymkomplexen an bestimmte mRNAs vermitteln und so entweder nachfolgend den Abbau der mRNA induzieren oder das Umschreiben der mRNA in Proteine beeinflussen.

13 Die sog. „messenger RNA“ (mRNA) ist die komplementäre Kopie einer kodierenden Gensequenz der DNA. Sie transportiert die Information ihres Gens aus dem Zellkern in das Zytoplasma, wo sie als Matrize der Proteinbiosynthese dient, d. h. DNA wird in die Aminosäuresequenz eines Proteins übersetzt. 
Neben den miRNAs gibt es andere kleine ncRNAs (22-30 Basenpaare lang), die vollkommen anders wirken - als Strukturgeber für die Ausbildung von Heterochromatin. Sie führen epigenetische Modifikationskomplexe an bestimmte Genomabschnitte heran, um so ortsgerichtet dichtes Chromatin auszubilden. Diese Vorgänge sind wichtig zur Ausbildung von Zentromer- und Telomerstrukturen wie auch zur Stilllegung der sehr häufig im Genom vorkommenden transposablen Elemente. ${ }^{14}$ Eine ganz besondere Klasse kleiner RNAs, die sog. piRNAs, erfüllen eine spezielle Kontrollaufgabe in Keimzellen. Sie sorgen für die Stilllegung aktiver springender Gene/Transposons in der Keimbahn und damit für den Stabilitätserhalt des Genoms.

Neben den kurzen RNAs spielen lange nicht-kodierende RNAs (lncRNA) wie XIST, AIR oder HOTAIR, die selbst als mRNAs gebildet werden, aber von denen kein Protein gebildet wird, eine bedeutende Rolle für die epigenetische Kontrolle. Die lncRNA XIST ist ein essenzieller Faktor für die epigenetische Stilllegung von Genen auf dem X-Chromosom (Gendosiskompensation) im Menschen (Clerc/Avner, 2006). AIR und HOTAIR steuern die epigenetische Kontrolle wichtiger entwicklungsspezifischer Gene (Statello et al., 2021).

Die volle Bedeutung (Funktion) und Vielfalt (Anzahl, Größe, Form) der ncRNAs für die epigenetische Steuerung ist bei Weitem noch nicht verstanden. Es wird jedoch beobachtet, dass funktionelle Veränderungen von Zellen an reproduzierbare Veränderungen im Vorkommen von miRNAs und lncRNAs geknüpft sind. In Krebszellen kommt es entsprechend zu einer krebsspezifischen Fehlregulation von miRNAs und lncRNAs. Diese Veränderungen der miRNA-Profile können gezielt für die Tumordiagnostik genutzt werden. Man beobachtet, dass krebsspezifische miRNA-Muster aus absterbenden Krebszellen selbst in das Blutserum gelangen. Daher wird intensiv an Verfahren gearbeitet, um ein nicht invasives (Früh-)Screening auf mögliche Tumorerkrankungen im Serum von Patienten durch miRNA-Profiling zu etablieren.

\subsubsection{Epitranskriptom}

Mit der Epitranskriptomik entsteht zurzeit ein neues wichtiges Arbeitsgebiet im Bereich der RNA-basierten Epigenetik. Die Methoden für die molekülgenaue Kartierung von RNA-Modifikationen sind noch wesentlich eingeschränkter als die DNA-Sequenzierungsmethoden, aber neue Ansätze werden zunehmend entwickelt (Li et al., 2016). Epigenetische Modifikation der RNA-Basen sind seit Langem vor allem im Bereich der

14 Im Gegensatz zum sog. Euchromatin ist Heterochromatin fest verpacktes, inaktives Chromatin. In der Regel betrifft das genarme Sequenzen sowie die Mitte (Centromere) und die Enden (Telomere) der Chromosomen. 
tRNAs ${ }^{15}$ bekannt, ihre genaue Kartierung und biologische Bedeutung in anderen RNAs ist aber bislang noch wenig erforscht (Wiener/Schwartz, 2021). Dies gilt insbesondere für mRNA-Modifikationen wie z. B. 6-methyl-Adenin, das durch Enzyme wie MettL3 („Writer“) gesetzt bzw. durch FOT („Eraser“) wieder entfernt werden kann. Die Bedeutung dieser Modifikation für die mRNA-Funktion ist noch zu klären.

\subsection{Epigenomische Technologien}

\subsubsection{Epigenomik: Vom Epigenomatlas zur Interpretation}

Die Epigenomik, d. h. die genomweite Kartierung epigenetischer Veränderungen mithilfe neuer NGS-Technologien, rückt zunehmend in den Vordergrund epigenetischer Forschung (Stunnenberg et al., 2016). Ermöglicht wurde die rasante Entwicklung dieses Fachgebietes durch den schnellen Fortschritt in der Anwendung komplexer NGS-unterstützter Verfahren. Wie oben bereits erwähnt, wurden Methoden wie ChIP-Seq für die Kartierung von Histon-Modifikationen und WGBS für die basengenaue Erfassung von DNA-Methylierung entwickelt (siehe 3.2.1 und 3.2.2). Weitere Verfahren ermöglichen die genomweite Vermessung der Chromatinzugänglichkeit. Mit Techniken wie ATAC-Seq ${ }^{16}$ (siehe auch unten) kann man die lokale Zugänglichkeit des Chromatins bestimmen und regulatorische Regionen in der Nähe von Genen kartieren. Eine neue Entwicklung in der Epigenomforschung sind Arbeiten zur dreidimensionalen Analyse von Genomen im Zellkern. ${ }^{17}$ Diese komplexen Verfahren liefern Daten darüber, wie sich Chromosomen im Zellkern falten und ordnen und wie dadurch Gene mit regulatorischen Elementen in eine räumliche Beziehung treten. Veränderungen dieser räumlichen Anordnungen haben z. T. nachhaltige Folgen für die epigenetische Genregulation.

15 Transfer-RNAs (tRNAs), sind kleine RNAs, die bei der Proteinbiosynthese eine zentrale Rolle spielen, indem sie Aminosäuren an die richtige Stelle transportieren.

16 Die Methode „ATAC-seq“ („Assay for Transposase-Accessible Chromatin using sequencing“) basiert auf einem Enzym namens Tn5-Transposase, welches zugängliche DNA schneiden kann. Das Enzym wird in isolierte Zellkerne eingebracht, in denen das Chromatin noch in seiner intakten Verpackungsstruktur vorliegt. Die Transposase schneidet das Chromatin in offenen, zugänglichen Bereichen, jedoch nicht bzw. weniger in dichter verpackten, von Nukleosomen geschützten Bereichen. Dann isoliert man die DNA der geschnittenen Fragmente und bestimmt sie durch Hochdurchsatzsequenzierung. Nach einer bioinformatischen Auswertung dieser Daten erhält man eine Anreicherungskarte entlang des Genoms/Chromosoms, wo exakt das Chromatin offen bzw. zugänglich ist.

17 Siehe unter: https://www.4dnucleome.org/ [19.08.2021] und https://spp2202.charite.de/en/ [19.08.2021]. 
Epigenomdaten sind hochkomplex, umfangreich und vielschichtig. Für ein komplettes Epigenom einer Zelle werden bis zu 10 einzelne epigenomische Datensätze erstellt, die im Nachgang integriert, $d$. h. übereinandergelegt und gemeinsam analysiert werden müssen. Aus dieser komplexen Datenstruktur ergeben sich neue Herausforderungen, die bisherige Genomdatendarstellungen bei Weitem übertreffen. Es mussten/müssen neue bioinformatische Techniken der Auswertung für die Darstellung etabliert werden. Zudem muss die Struktur existierender genomischer Datenbanken erweitert werden, um Epigenomdaten sinnvoll ablegen und nutzen zu können. Die breite internationale Vernetzung von Forschungsaktivitäten und der koordinierte Austausch experimenteller Verfahren und Protokolle hat hier zu einer Bündelung der Aktivitäten geführt. Die weltweit erstellten epigenomischen Daten können so gegenwärtig vom Internationalen Humanen Epigenomkonsortium (IHEC) ${ }^{18}$ in einem Standard vereinigt werden mit dem Ziel, einen umfassenden und nachhaltigen Epigenomatlas ${ }^{19}$ menschlicher Zellen zu erstellen. Konsortien wie IHEC und ENCODE stellen zudem ein Kompendium von Arbeitshilfen zur Verfügung, ${ }^{20}$ die es erlauben, die komplexen Daten vereinfacht darzustellen, um sie für funktionelle Interpretationen in der Grundlagenforschung bzw. der klinischen Forschung zu nutzen.

Bis vor wenigen Jahren benötigte man für die Erstellung komplexer Epigenomkarten noch Zellzahlen von $>100.000$. Mittlerweile sind einige der Verfahren mit deutlich geringeren Zellzahlen durchführbar. Dies führt zu deutlich reduzierten Kosten pro Epigenom, einer flexibleren Nutzbarkeit auch für Zellen, die nur in geringen Zahlen gewonnen werden können, und einer breiteren Anwendung in der Grundlagenforschung. Für einige der Methoden ergeben sich realistische Möglichkeiten, sie in naher Zukunft für die angewandte, klinische Forschung zu nutzen.

Einige der Epigenomkartierungsverfahren wie z. B. die genomweite Kartierung von DNA-Methylierung (WGBS) oder von offenem Chromatin (ATAC-Seq bzw. NOMeSeq) sind mittlerweile so weiterentwickelt worden, dass hochkomplexe Teilepigenomdaten aus einzelnen Zellen gewonnen werden können. Für ATAC-Seq sind bereits kommerzielle Verfahren auf halbautomatisierten Plattformen parallel zu RNA-Seq durchführbar. Zusammen mit Einzelzelltranskriptomdaten (RNA-Seq) eröffnet diese Entwicklung

18 Das International Human Epigenom Consortium (IHEC) vereint Forschungsnetzwerke aus vielen Nationen weltweit. Koordiniert vom Kanadischen Netzwerk CENMT sind wichtige IHEC-Partner das US-Programm ENCODE, das EPIGENOM-ROADMAP-Programm des NIH, das EU-Programm BLUEPRINT, das japanische Programm CREST, das deutsche Programm DEEP und viele andere (siehe unter: http://ihec-epigenomes.org/research/projects/ [19.08.2021]).

19 Siehe unter: https://epigenomesportal.ca/ihec/ [19.08.2021].

20 Siehe unter: http://ihec-epigenomes.org/research/tools/ [19.08.2021]. 
einen neuen Zugang zu einer einzelzellbezogenen multimodalen (auf mehreren Ebenen durchführbaren) funktionellen Diagnostik. Die gemeinsame Interpretation komplexer Epigenomdaten (auch Einzelzellepigenomdaten) und Einzelzelltranskriptomdaten führt gegenwärtig zu einem Schub in der Entwicklung neuer Erkenntnisse und neuer bioinformatischer Interpretationsansätze unter Verwendung komplexer statistischer und maschineller Lernverfahren (Walter/Schickl, 2019). Die daraus gewonnenen Erkenntnisse werden in naher Zukunft Eingang finden in eine funktionsbasierte und personenbezogene molekulare Diagnostik und in die weitere Entwicklung neuer zellspezifischer (epigenetischer) Therapien.

\subsubsection{Epigenetische Therapieansätze}

Epigenetische Prozesse eröffnen neue Möglichkeiten für die Entwicklung molekularer Therapien, die darauf abzielen, fehlerhafte epigenetische Veränderungen in lebenden Zellen so umzuprogrammieren, dass Zellen in einen gesunden Grundzustand zurückgeführt werden.

In den vergangenen Jahren wurde eine Reihe von Substanzen untersucht, die spezifisch Histon- oder DNA-modifizierende Enzyme angreifen und deren Funktion beeinflussen. Als Folge werden epigenetische Modifikationen genomweit verändert. Viele dieser Substanzen wurden vor allem für die Krebstherapie entwickelt. Einige befinden sich noch in der klinischen Testung, andere werden bereits für bestimmte Krebsarten routinemäßig klinisch eingesetzt. Die Wirkweise dieser Substanzen ist analog zu Chemotherapeutika genomweit und erfolgt nicht zielgerichtet. Dies führt zu Nebenwirkungen, da auch gesunde Zellen epigenetisch verändert werden. Trotzdem scheinen einige Substanzen eine erhebliche unterstützende Therapiewirkung zu zeigen. Epigenetisch wirkende Substanzen werden zunehmend unterstützend in niedrigerer Dosierung in Kombination mit anderen zellspezifischen Wirkstoffen verabreicht (Jones et al., 2019).

\subsubsection{Epigenomeditierung - der neue Weg zu einer zellbasierten Therapie?}

In jüngster Zeit hat sich die Epigenomeditierung als eine vollkommen neue Perspektive epigenetischer Therapie entwickelt. Epigenomeditierung umschreibt biotechnologische Verfahren, in denen epigenetisch wirkende Enzyme zielgerichtet an bestimmte Gene herangeführt werden, um so eine genspezifische epigenetische Umprogrammierung zu induzieren, wodurch genomweite Nebenwirkungen entfallen. Einige Versuche weisen darauf hin, dass man mit solchen Verfahren durchaus nachhaltige epigenetische Umprogrammierungen und Funktionsveränderungen in den Zellen erwirken kann. Für 
die Epigenomeditierung nutzt man modifizierte Verfahren, die sich der CRISPR/Cas9Genschere $^{21}$ (siehe Fehse et al., Kap. 9) bedienen. Die modifizierenden Enzyme werden direkt an das enzymatisch inaktive dCas9 gekoppelt und dieser Komplex mithilfe einer CRISPR-Guide-RNA gezielt an bestimmte Orte gebracht. In unmittelbarer Nachbarschaft der durch die Guide-RNA definierten Zielstelle kommt es dann zu Modifikationsveränderungen, die abhängig vom eingesetzten Enzym ein Löschen, ein neues Setzen oder auch ein Lesen epigenetischer Modifikationen zur Folge hat.

Die Epigenomeditierung bietet mit dieser flexiblen Anwendung eine breite Palette von Anwendungsmöglichkeiten. Diese reicht von funktionellen Analysen regulatorischer Abschnitte im Genom bis hin zu zellgerichteten, gentherapeutischen Ansätzen, um Zellfunktionen zu verbessern oder kranke Zellen umzuprogrammieren. Im Gegensatz zur Genomeditierung sind die Gefahren von Off-Target-Effekten ${ }^{22}$ bei der Epigenomeditierung zu vernachlässigen (Ansari et al., 2021). Eine Reihe von Versuchen zeigen, dass epigenetische Editierung zu nachhaltigen lokalen epigenetischen Veränderungen führt und damit als Ansatz zu einer Umprogrammierung von Zellen angewandt werden kann. Mithilfe der Epigenomeditierung könnten z. B. dem Körper entnommene Zellen in vitro epigenetisch auf ihre ursprüngliche Funktionalität reprogrammiert werden. Diese epigenetische Reprogrammierung autologer Zellen ist vor allem im Bereich von Immunzellen denkbar, um hier z. B. die Reservoirs funktioneller bzw. responsiver Immunzellen wiederherzustellen (Singh et al., 2019).

\subsection{Epigenetik und Nachhaltigkeit epigenetischer Veränderungen}

\subsubsection{Epigenetik und Anpassung}

Epigenetische Steuerung ist nicht nur als ein Aus- oder Anschalten von Genen zu betrachten, sondern als ein Mechanismus oberhalb der Gene, der eine begrenzte Modulierbarkeit genetischer Information ermöglicht. Epigenetische Modifikationen bestimmen quasi den Nutzungsrahmen der genetischen Information. Epigenetische

21 Das System der CRISPR/Cas9-Genschere ist eine gentechnische Methode, die es ermöglicht, selektive Veränderungen an der DNA vorzunehmen. Mithilfe einer sog. Guide-RNA, welche den zu verändernden Genabschnitt erkennt, wird das Protein Cas 9 präzise zur gewünschten Zielsequenz gebracht und kann dort die DNA schneiden. Im Zusammenspiel mit zelleigenen Reparatursystemen können auf diese Weise bestimmte DNA-Abschnitte bzw. Gene gezielt entfernt, verändert oder hinzugefügt werden.

22 Ungewollte Veränderungen der DNA an anderen Stellen im Genom, die nicht den Zielregionen entsprechen. 
Mechanismen sind daher aus dem Blickwinkel einer quantitativen Biologie zu betrachten und leisten einen Beitrag zur Anpassung des Genoms an die Umwelt.

Für die Mehrzahl der Gene in unserem Genom ist der epigenetische Anpassungsrahmen allerdings sehr begrenzt. Wie bereits oben erläutert, dienen epigenetische Prozesse primär der Steuerung von Genen im Verlauf der Entwicklung und der Ausbildung der Zellidentität. Epigenetisch gesteuerte Entwicklungs- und Determinationsprozesse von Zellen sind ursächlich genetisch bestimmt und daher nur begrenzt responsiv in Bezug auf Veränderungen. Im Verlauf des Lebens und des Alterns kommt es jedoch zu feststellbaren Veränderungen und begrenzten epigenetischen Anpassungen in Genprogrammen. Der Anpassungsrahmen scheint von Organismus zu Organismus unterschiedlich zu sein. Standortgebundene Organismen wie Pflanzen haben eine breitere Palette epigenetischer Anpassungsstrategien entwickelt und können diese zudem in begrenztem Ausmaß vererben.

Im Menschen sind die Anpassungsrahmen enger gesteckt und die epigenetische Anpassungsfähigkeit vermutlich stärker an die individuelle genetische Ausstattung gekoppelt. Es gibt jedoch eine Reihe von Studien und Hinweisen, die zeigen, dass traumatische psychische Ereignisse, Drogensucht und andere starke externe Reize bleibende epigenetische Signaturen im Genom hinterlassen (Hamilton/Nestler, 2019).

\subsubsection{Epigenetische transgenerationelle Vererbung}

Ein Grundcharakteristikum der Epigenetik ist ihre Vererbbarkeit, d. h. eine über Zellteilungen stabile Weitergabe epigenetischer Markierungen auf Tochterchromosomen. Sowohl Histon-Modifikationen als auch DNA-Methylierungsmuster bleiben so über Mitosen (Zellteilungen) hinweg in dem sich entwickelnden Organismus stabil erhalten. Eine Vererbung von Modifikationen der Eltern auf die Kinder, d. h. über die Keimbahn und die haploiden Keimzellen, ist möglich, aber nicht für alle Organismen zweifelsfrei nachgewiesen (zu epigenetischer Vererbung siehe Jawaid/Mansuy, Kap. 12, und Alex/ Winkler, Kap. 13). In viel zitierten Beispielen der Grundlagenforschung sind solche epigenetischen Vererbungsereignisse in Säugern (Mausmodell) und dem Menschen zumeist an lokale genetische Veränderungen gekoppelt (Horsthemke, 2018). Trotzdem werden solche Beispiele immer wieder bemüht, um neue Konzepte der Vererbbarkeit epigenetischer Umweltanpassung über Generationen hinweg zu entwickeln. Die meisten dieser neolamarckistischen Szenarien adaptiver „Epimutationen“ haben bei genauerem Hinsehen jedoch oft nur eine sehr dünne Datenbasis.

Im Menschen gibt es bislang keine klaren Beweise für regulär vererbte epigenetische Effekte durch die Keimbahn (Horsthemke, 2018). Viele Beobachtungen und Berichte 
transgenerationaler Effekte beruhen auf epigenetischen Interpretationen empirischer Erhebungen (z. B. Krankheitsstatistiken). Zudem ist die molekulare Basis einer transgenerationellen Vererbbarkeit im Menschen (anders als bei Pflanzen) sehr unklar. Gegen eine einfache Vererbung epigenetischer Modifikationen über die Keimbahn spricht die Tatsache, dass eine extensive epigenetische Reprogrammierung sowohl in den Keimzellen als auch nach der Befruchtung in der frühen Embryonalentwicklung stattfindet. Fehler im epigenetischen Programm werden so sehr systematisch gelöscht. Die im Tiermodell beobachtete ernährungsbedingte Vererbung einer epigenetischen Markierung im „viable yellow“-Gen von Agouti-Mäusen ${ }^{23}$ zeigen bei genauer Betrachtung, dass epigenetische Programme hier eng an eine genetische Mutation und den genetischen Hintergrund der Tiere gekoppelt sind (Whitelaw/Whitelaw, 2006; Horsthemke, 2018).

Gleichzeitig gibt es Hinweise darauf, dass eine frühe Prägung der (ererbten) elterlichen Genome durch Faktoren des maternalen Eizytoplasmas einen langfristigen Einfluss auf die individuelle epigenetische Ausprägung von Genen haben kann. Die Präsenz kleiner ncRNAs oder bestimmter regulatorischer Proteine, die über das Eizellplasma mit den elterlichen Chromosomen in Kontakt treten, könnten so durchaus einen nachhaltigen Einfluss auf die Genregulation ausüben. Ein jüngstes Beispiel aus der Immunologie deutet an, dass es bei Mäusen zu einer transgenerationalen, vermutlich epigenetisch gesteuerten Übertragung einer „trainierten“ (d. h. erworbenen) Immunitätsantwort und damit einer erhöhten Resistenz (Abwehr) gegen bakterielle Infektionen kommen kann (Katzmarski, im Druck).

In Pflanzen sind die Hinweise auf eine transgenerationelle epigenetische Vererbung häufiger zu beobachten. In Pflanzen kommt es im Gegensatz zu Säugern (z. B. Menschen) zu keiner vollständigen Löschung epigenetischer Modifikationen in den Keimzellen. Eine epigenetische Vererbung von Anpassungen an veränderte Umweltbedingungen kann in einigen Nutzpflanzen über Generationen hinweg erfolgen und wird zunehmend in der Züchtungsforschung berücksichtigt. Ein prägnantes Beispiel für eine spontan entstandene und vererbte epigenetische Modifikation, die über viele Generationen hinweg erhalten geblieben ist, ist die bereits vor über 250 Jahren von Carl von Linné und Goethe beschriebene epigenetische Blütenmutante „Peloria“ des Löwenmäulchens (Cubas et al., 1999).

23 Agouti-Mäuse tragen eine spezielle Variante namens ,agouti viable yellow“ ( $a^{\text {vy }}$ ) eines die Fellfarbe bestimmenden Gens. Je stärker dieses Gen methyliert ist, desto dunkler ist die Fellfarbe - und desto gesünder ist die Maus. Eine Supplementierung der Ernährung der Mütter mit methylierenden Molekülen wie Methionin, Folsäure und Zink führt zu stärker methylierten $a^{\mathrm{vy}}$-Genen der Nachkommen sogar bis in die Enkelgeneration. Dieses Experiment wird oft als Beispiel für den epigenetisch vermittelten Einfluss des Lebensstils auf die Gesundheit der nächsten Generation(en) herangezogen. 


\subsection{Perspektiven epigenetischer Forschung}

Die Epigenetik und epigenetische Technologien haben auf multiplen Ebenen Einzug in die Biologie, die Biomedizin und die Rote und Grüne Biotechnologie gefunden. Epigenetische Prozesse spielen eine zentrale Rolle für die Gensteuerung und damit für die differenzielle Funktionssteuerung des Genoms in vielzelligen Organismen. Genomweite epigenetische Daten, die mittlerweile routinemäßig erstellt werden können, bieten eine neue funktionelle Einordnung zur Steuerung und Fehlsteuerung zellulärer Prozesse. Sie leisten einen wichtigen Beitrag für die molekulare Diagnostik und eröffnen zuvor unbekannte Wege für Therapien. Die Epigenomeditierung ist ein äußerst spannendes neues Forschungsfeld der Epigenetik. Gleiches gilt auch für die Einzelzellepigenomik.

Epigenetische Anpassungsprozesse können im Menschen zu nachhaltigen physiologischen Veränderungen beitragen. In der Gesundheitsprävention, der Psychologie und den Sozialwissenschaften werden epigenetische Mechanismen bereits heute als persönlichkeitsbeeinflussende Faktoren diskutiert. Der Diskurs beruht allerdings leider immer noch auf sehr wenigen Beispielen und Daten. Die Argumentationsketten, die auf Daten der empirischen Studien wie der „Dutch Hunger Winter“-Studie oder der Överkalix-Studie beruhen, sind noch immer nicht durch weitere fundierte Studien belegt. Auch entsprechen die in vielen Studien angewandten epigenetischen Methoden nicht den notwendigen kontrollierten Standards und Daten werden oft sehr gewagt interpretiert.

Generell ist im Umgang mit epigenetischen Daten und ihrer Interpretation sehr umsichtig vorzugehen. Es gibt klare Hinweise, dass epigenetische Daten Informationen zum Lebensstil des Menschen, sein biologisches Alter und bestimmte Erkrankungen widerspiegeln. Epigenomische Daten sollten daher mit Sorgfalt interpretiert und bewertet werden, um Stigmatisierungen zu vermeiden.

In Zukunft sollte der Epigenetik und epigenetischen Konzepten ein größerer Stellenwert im aktuellen (natur-)philosophischen und gesellschaftswissenschaftlichen Diskurs zu humanbiologischen Fragen eingeräumt werden. Es ist dabei wichtig, einen starken Fokus auf die Vermittlung der Grundlagen epigenetischer Konzepte und der aus ihnen abgeleiteten Theorien zu legen.

\subsection{Literaturverzeichnis}

Ansari, I et al. (2021): CRISPR/Cas mediated epigenome editing for cancer therapy. In: Semin Cancer Biol. S1044-579X(20): 30278-9. DOI: 10.1016/j.semcancer.2020.12.018.

Arand, J. et al. (2015): Selective impairment of methylation maintenance is the major cause of DNA methylation reprogramming in the early embryo. In: Epigenetics Chromatin 8(1): 1. 
Azad, N. et al. (2013): The future of epigenetic therapy in solid tumours - lessons from the past. In: Nat Rev ClinOncol 10(5): 256-266.

Baulcombe, D. (2004): RNA silencing in plants. In: Nature 431(7006): 356-363.

Bernstein, B. E. et al. (2006): A bivalent chromatin structure marks key developmental genes in embryonic stem cells. In: Cell 125(2): 315-326.

Bernstein, B. E. et al. (2010): The NIH roadmap epigenomics mapping consortium. In: Nature Biotechnology 28: 1045-1048.

Birney, E. et al. (2016): Epigenome-wide association studies and the interpretation of disease-omics. In: Plos Genetics 12(6): e1006105. DOI: 10.1371/journal.pgen.1006105.

Chi, A. S./Bernstein, B. E. (2009): Developmental biology. Pluripotent chromatin state. In: Science 323(5911): 220-221.

Clerc, P./Avner, P. (2006): Random X-chromosome inactivation. Skewing lessons for mice and men. In: CurrOpin Genet Dev 16(3): 246-253.

Corpet, A./Almouzni, G. (2009): Making copies of chromatin. The challenge of nucleosomal organization and epigenetic information. In: Trends Cell Biol 19(1): 29-34.

Cubas, P. et al. (1999): An epigenetic mutation responsible for natural variation in floral symmetry. In: Nature 401(6749): 157-161.

ENCODE Project Consortium et al. (2012): An integrated encyclopedia of DNA elements in the human genome. In: Nature 489(7414): 57-74.

Ficz, G. et al. (2013): FGF signaling inhibition in ESCs drives rapid genome-wide demethylation to the epigenetic ground state of pluripotency. In: Cell Stem Cell 13(3): 351-359.

Gasparoni, G. et al. (2018): DNA methylation analysis on purified neurons and glia dissects age and Alzheimer's disease-specific changes in the human cortex. In: Epigenetics Chromatin 11(1): 41. DOI: 10.1186/s13072-018-0211-3.

Gehring, M. et al. (2009): DNA demethylation by DNA repair. In: Trends Genet 25(2): 82-90.

Habibi, E. et al. (2013): Whole-genome bisulfite sequencing of two distinct interconvertible DNA methylomes of mouse embryonic stem cells. In: Cell Stem Cell 13(3): 360-369.

Hamilton, P.J./Nestler, E. J. (2019): Epigenetics and addiction. In: Curr Opin Neurobiol. 59: 128-136 DOI: 10.1016/j.conb.2019.05.005.

Heard, E./Martienssen, R. A. (2014): Transgenerational epigeneticinheritance: myths and mechanisms. In: Cell 157(1): 95-109.

Henderson, I. R./Jacobsen, S. E. (2007): Epigenetic inheritance in plants. In: Nature 447(7143): 418-424. Hirsch, S. et al. (2012): Epigenetic variation, inheritance, and selection in plant populations. In: Cold Spring Harb Symp Quant Biol 77: 97-104.

Holoch, D./Moazed, D. (2016): RNA-mediated epigenetic regulation of gene expression. In: Nat Rev Genet. 16(2): 71-84. DOI: 10.1038/nrg3863.

Horsthemke, B. (2018): A critical view on transgenerational epigenetic inheritance in humans. In: Nat Commun. 9(1): 2973. DOI: 10.1038/s41467-018-05445- 5. 
Horvath, S. (2013): DNA methylation age of human tissues and cell types. In: Genome Biology 14. DOI: 10.1186/gb-2013-14-10-r115.

Jones, P. A. et al. (2019): Epigenetic therapy in immune-oncology. In. Nat Rev Cancer 19(3): 151-161. DOI: 10.1038/s41568-019-0109-9.

Karnik, R./Meissner, A. (2013): Browsing (epi)genomes: a guide to data resources and epigenome browsers for stem cell researchers. In: Cell Stem Cell 13(1): 14-21.

Katzmarski, N. (im Druck): Transmission of trained immunity and heterologous resistance to infections across generations. In: Nat Immunol.

Knippers, R./Nordheim, A. (2015): Molekulare Genetik. 10 Aufl. Thieme Verlag, Stuttgart.

Kouzarides, T. (2007): Chromatin modifications and their function. In: Cell 128(4): 693-705.

Kubicek, S. et al. (2006): The role of histone modifications in epigenetic transitions during normal and perturbed development. In: Ernst Schering Res Found Workshop (57): 1-27.

Lewin, B. (1998): The mystique of epigenetics. In: Cell 93(3): 301-303.

Li, X et al. (2016): Epitranscriptome sequencing technologies: Decoding RNA modifications. In: Nat Methods 14(1): 23-31. DOI: 10.1038/nmeth.4110.

Lyko, F. et al. (2010): The honey bee epigenomes: Differential methylation of brain DNA in queens and workers. In: PloS Biology 9(1). DOI: 10.1371/journal.pbio.1000506.

Maleszka, R. (2008): Epigenetic integration of environmental and genomic signals in honey bees. The critical interplay of nutritional, brain and reproductive networks. In: Epigenetics 3(4): 188-192.

Miao, Z. et al. (2015): Altering 5-hydroxymethylcytosine modification impacts ischemic brain injury. In: Hum Mol Genetics 24(20): 5855-5866. DOI: 10.1093/hmg/ddv307.

Mikkelsen, T. S. et al. (2007): Genome-wide maps of chromatin state in pluripotent and lineage-committed cells. In: Nature 448(7153): 553-560.

Roadmap Epigenomics Consortium et al. (2015): Integrative analysis of 111 reference human epigenomes. In: Nature 518: 317-330.

Scherer, M. et al. (2021): Identification of tissue-specific and common methylation quantitative trait loci in healthy individuals using MAGAR. In: Epigenetics Chromatin 14(1): 44. DOI: 10.1186/s13072021-00415-6.

Seisenberger, S. et al. (2013): Conceptual links between DNA methylation reprogramming in the early embryo and primordial germ cells. In: CurrOpin Cell Biol 25(3): 281-288.

Singh, D. D. et al. (2019): CRISPR/Cas9 guided genome and epigenome engineering and its therapeutic applications in immune mediated diseases. In: Semin Cell Dev Biol. 96: 32-43. DOI: 10.1016/j. semcdb.2019.05.007.

Souren, N. Y. et al. (2019): DNA methylation signatures of monozygotic twins clinically discordant for multiple sclerosis. In: Nat Commun 10: 2094.

Statello, L. et al. (2021): Gene regulation by long non-coding RNAs and its biological functions. In: Nature Reviews Molecular Cell Biology 22: 96-118. 
Stunnenberg, $\mathrm{H}$ et al., (2016): The International Human Epigenome Consortium: A blueprint for scientific collaboration and discovery. In: Cell 167(5): 1145-1149. DOI: 10.1016/j.cell.2016.11.007.

Varga-Weisz, P. D./Becker, P. B. (2006): Regulation of higher-order chromatin structures by nucleosome-remodelling factors. In: Curr Opin Genet Dev 16(2): 151-156.

Walter, J/Schickl, H. (2019): Einzelzellanalyse in Forschung und Medizin - Eine Stellungnahme der interdisziplinären Arbeitsgruppe Gentechnologiebericht. Berlin Brandenburgische Akademie der Wissenschaften, Berlin.

Wang, Y. et al. (2006): Functional CpG methylation system in a social insect. In: Science 314(5799): 645-647.

Weisenberger, D. J. (2014): Characterizing DNA methylation alterations from The Cancer Genome Atlas. In: J Clin Invest 124(1): 17-23.

Whitcomb, S. J. et al. (2007): Polycomb Group proteins. An evolutionary perspective. In: Trends Genet 23(10): 494-502.

Whitelaw, N. C./Whitelaw, E. (2006): How lifetimes shape epigenotype within and across generations. In: Hum Mol Genet 15(2): R131-R137.

Wiener, D./Schwartz, S. (2021): The epitranscriptome beyond m(6)A. In: Nat Rev Genet. 22(2): 119-131. DOI: $10.1038 / \mathrm{s} 41576-020-00295-8$.

Wossidlo, M. et al. (2011): 5-Hydroxymethylcytosine in the mammalian zygote is linked with epigenetic reprogramming. In: Nat Commun 2: 241.

Youngson, N. A./Whitelaw, E. (2008): Transgenerational epigenetic effects. In: Annu Rev Genomics Hum Genet 9: 233-257.

Zheng, X. et al. (2008): ROS3 is an RNA-binding protein required for DNA demethylation in Arabidopsis. In: Nature 455(7217): 1259-1262. 